$\frac{1}{0}$
$\vdots$
$z$
$\vdots$
$\vdots$
$\vdots$

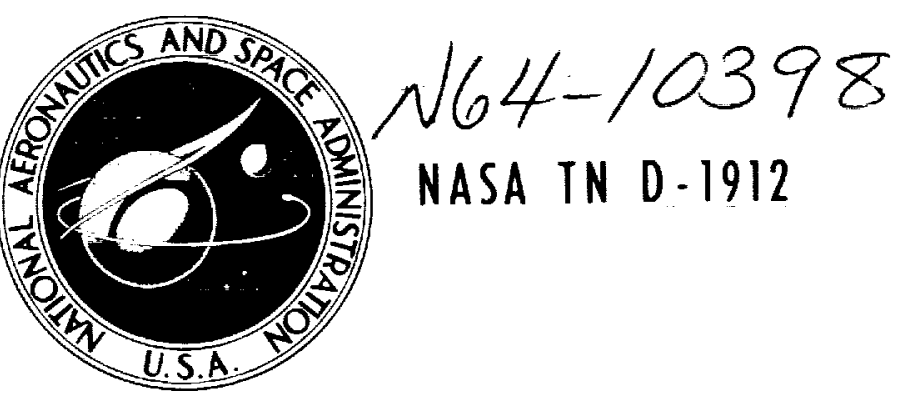

\title{
ACOUSTIC HEATING OF THE POLAR NIGHT MESOSPHERE
}

by Kaichi Maeda

Goddard Space Flight Center

Greenbelt, Maryland

LIBRARY Administration National Aeronautics and Space Admin
Washington 25,0 . C.

national aeronaUtics and SPACE ADMINISTRation - WaShINGTON, D. C. - NOVEMbER 1963 

TECHNICAL NOTE D-1912

ACOUSTIC HEATING OF THE

POLAR NIGHT MESOSPHERE

By Kaichi Maeda

Goddard Space Flight Center

Greenbelt, Maryland

NATIONAL AERONAUTICS AND SPACE ADMINISTRATION 



\title{
ACOUSTIC HEATING OF THE POLAR NIGHT MESOSPHERE
}

\author{
by \\ Kaichi Maeda \\ Goddard Space Flight Center
}

SUMMARY

As a part of the dynamical heating of the upper atmosphere, which has been emphasized by Hines, the acoustic heating of the upper air is reinvestigated, particularly the warming of the polar night mesosphere.

It is shown that because of the relatively small transmissivity of the thermosphere for long period sound waves, most acoustic heating does not take place above the $200 \mathrm{~km}$ level, but rather below $100 \mathrm{~km}$ or around the mesopause, and that although the acoustic output power from the polar jet stream is more than $10^{5}$ times larger in winter than in summer, acoustic heating is not sufficient to compensate for the cooling rate around the mesopause in winter, unless the wind velocity of the polar night jet stream continually exceeds $200 \mathrm{~m} / \mathrm{sec}$. 



\section{CONTENTS}

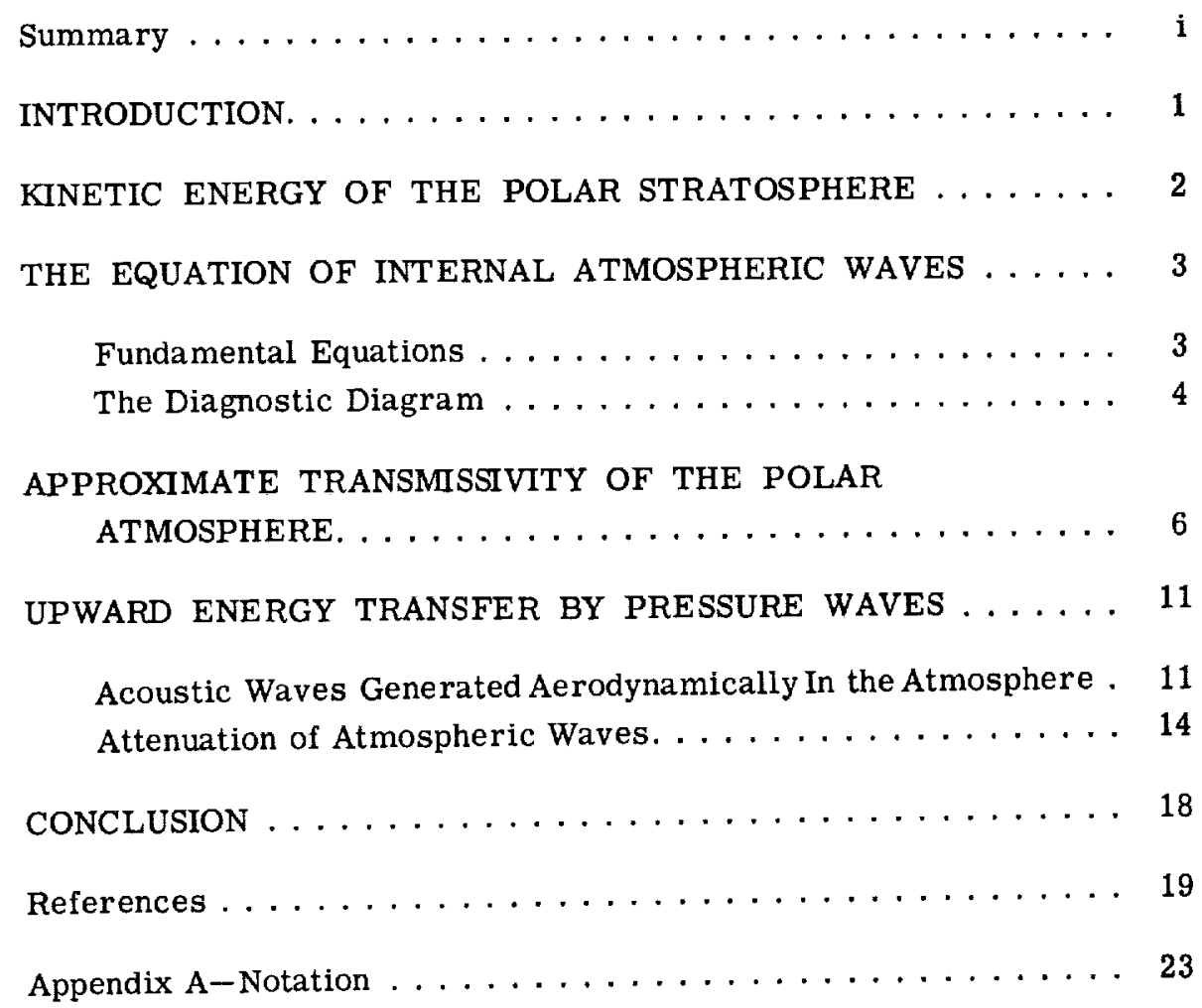





\title{
ACOUSTIC HEATING OF THE POLAR NIGHT MESOSPHERE
}

\author{
by \\ Kaichi Maeda \\ Goddard Space Flight Center
}

\section{INTRODUCTION}

An effective heating mechanism for the polar mesosphere, which is warmer in winter than in summer, is Kellogg's chemical heating through the recombination of atomic oxygen (References 1, 2, and $3)$. Although the velocity of subsidence required for this process is significantly less than that required for adiabatic heating alone, it must still be of the order of $0.1 \mathrm{~cm} / \mathrm{sec}$ near the $60-90 \mathrm{~km}$ level.

On the other hand, theoretical calculations by Haurwitz (Reference 4) indicate an upward rather than a downward flow in this region. And although Sawada (1961) has questioned Haurwitz's omission of certain inertia terms in his basic equations, a recent analysis by Kochanski (Reference 5) of rocket data relating to mesospheric circulation shows good agreement with Haurwitz's results.

Rocket soundings by Nordberg and Smith (Reference 6) have occasionally measured very warm wintertime mesosphere temperatures even in the middle latitudes, where subsidences are unlikely but very strong westerlies in the $40-80 \mathrm{~km}$ region appear to be associated.

Hines (References 7 and 8 ) has suggested that the increase of temperature in the polar night mesosphere could be explained by dynamical heating. Gassard (Reference 9) and Blamont and Jage (Reference 10 ) have found evidence of upward propagation of tropospheric disturbances into the ionosphere.

The possibility of acoustic heating of the ionosphere was discussed by Daniel (Reference 11), who considered the noise produced by the sea surface as an energy source. However, Eckart (Reference 12) showed that pressure waves from this source are completely ineffective in transferring energy up to such high altitudes. This has recently been confirmed by Cook and Young (Reference 13). The amount of acoustic heating of the ionosphere is also estimated by Golitsyn (Reference 14), using tropospheric sources. He arrives at an upward energy flux of the order of $10^{-2} \mathrm{erg} / \mathrm{cm}^{2} \mathrm{sec}$, which is insufficient to cause the observed heating. Moreover, Golitsyn did not consider the reflection of acoustic energy due to the vertical temperature distribution in the atmosphere.

In this paper, the contribution of aerodynamically produced atmospheric acoustic waves to the warming of the polar night mesosphere is reexamined, with the polar night jet stream in the 
stratosphere as the source, and with the thermal structure of the polar upper atmosphere, playing a part in propagation and absorption.

It should be noticed that the largest portion of the kinetic energy of the atmosphere is in the troposphere, where the air density is greatest, and is of the order of $10^{3} \mathrm{ergs} / \mathrm{cm}^{3}$. If this tropospheric kinetic energy is not trapped effectively within the troposphere, the earth's atmosphere at ionospheric heights should reach very high temperatures of the order of $10^{5} \mathrm{~K}$. However, Charney and Drazin (Reference 15) have shown that the escape of large amounts of planetary wave energy from the tropospheric layer into the upper atmosphere is prevented throughout most of the year by the large westerly zonal wind systems above the tropopause, except for short periods in the spring and autumn.

\section{KINETIC ENERGY DENSITY OF THE POLAR STRATOSPHERE}

Owing to the development of the polar night vortex and jet stream, the kinetic energy of the polar stratosphere increases remarkably during the polar nights. As may be the case for the solar corona, some part of this kinetic energy may be transferred upward by means of internal pressure waves.

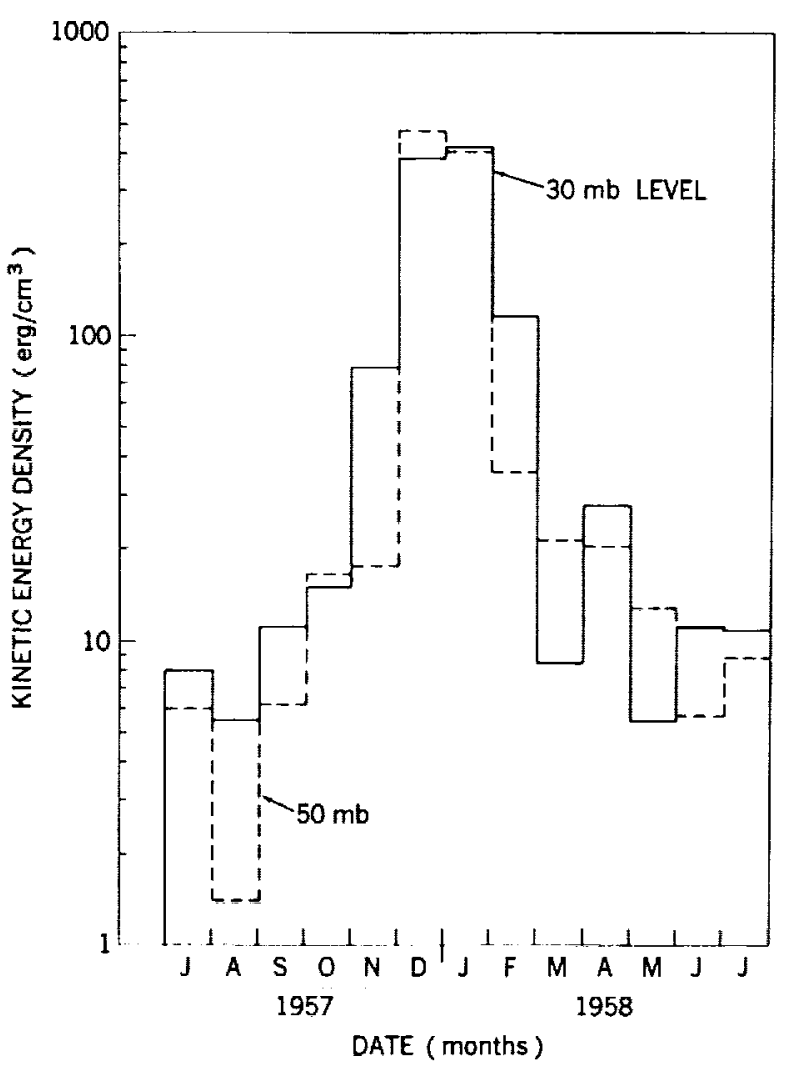

Figure 1-Monthly averages of kinetic energy density above Ft. Churchill $\left(59^{\circ} \mathrm{N}\right.$ geographic latitude) at 30 $\mathrm{mb}$ (solid lines) and at $50 \mathrm{mb}$ (dashed lines) during the period from July 1957 to July 1958.
According to Boville, Wilson and Hare (Reference 16), the kinetic energy density of zonal wind systems between $60 \% \mathrm{~N}$ and $80^{\circ} \mathrm{N}$ at 25 and 500 $\mathrm{mb}$ increases significantly during the wintertime (from December until March). The kinetic energy density corresponding to the winter peak of the basic zonal flow is of the order of 200 and $10^{3}$ $\mathrm{ergs} / \mathrm{cm}^{3}$ at the 25 and $500 \mathrm{mb}$ levels, respectively.

Figure 1 shows monthly averages (Reference 17) of kinetic energy densities during the period from July 1957 to July 1958 at $30 \mathrm{mb}$ (solid lines) and at $50 \mathrm{mb}$ (dashed lines) above Ft. Churchill $\left(59^{\circ} \mathrm{N}\right.$ geographic). This increase of kinetic energy in the upper stratosphere in wintertime is mainly due to the development of the polar night jet stream (Reference 18).

The dissipation of the energy of jet streams, as well as any strong wind system in the atmosphere, is mainly due to friction in the boundary layers, which cause the turbulent motion to decay into small eddies in the surrounding mediums. These eddies decay further into thermal motion and cause local heating. However, some part of the kinetic energy in turbulent motion in jet flow can propagate into the upper 
atmosphere in the form of pressure waves. Owing to the exponential decrease of air density with height, the amplitudes of those propagating pressure waves grow rapidly at high altitudes and approach shock-wave magnitudes, i.e. dissipation becomes non-linear.

\section{THE EQUATION OF INTERNAL ATMOSPHERIC WAVES}

\section{Fundamental Equations}

The equation of internal atmospheric waves is derived from the following three fundamental equations: the equation of motion

$$
\frac{\mathrm{D} \overrightarrow{\mathrm{V}}}{\mathrm{Dt}}+\frac{1}{\bar{\rho}} \vec{\nabla} \overline{\mathrm{p}}+\overrightarrow{\mathrm{g}}=\overrightarrow{\mathrm{f}}
$$

the equation of continuity

$$
\frac{\mathbf{D}}{\mathrm{Dt}}\left(\frac{\mathbf{1}}{\bar{\rho}}\right)=\frac{1}{\bar{\rho}} \vec{\nabla} \cdot \overrightarrow{\mathrm{v}}
$$

and the equation of thermodynamics

$$
\frac{D_{\mathrm{p}}}{\mathrm{Dt}}=c^{2} \frac{\mathrm{D}_{\bar{P}}}{\bar{D} \mathrm{t}}
$$

Since the source of disturbance is extended along a certain latitude, we can treat the problem in two dimensions and specify the coordinates within a meridional plane. Let $\mathrm{x}$ be the horizontal (southward) and $z$ the vertical (upward).

In the first approximation, the Coriolis force and external forces, except gravity, are neglected. The equation of motion (Equation 1) then becomes

$$
\rho_{0} \frac{\partial u}{\partial t}=-\frac{\partial \mathbf{p}}{\partial \mathbf{x}}
$$

and

$$
\rho_{0} \frac{\partial w}{\partial t}=-\frac{\partial p}{\partial z}-g \rho
$$

The equation of continuity (Equation 2) for the first order approximation is

$$
\frac{\partial \rho}{\partial t}+w \frac{\partial \rho_{0}}{\partial z}=-\rho_{0} x
$$


where $\chi=\chi(\mathrm{x}, \mathrm{z}, \mathrm{t})$ is the velocity divergence as defined in the previous section. Using Equation 4, the equation of thermodynamics (Equation 3 ) can be written as

$$
\frac{\partial p}{\partial t}+\left(c^{2} x-w g\right) \rho_{0}=0
$$

The waves travelling in the flat atmosphere can be found by assuming that $u, w, p$ and $\rho$ are proportional to $\mathrm{e}^{\mathrm{i}(\omega t \mathrm{k} x)}$. Then, the equation for vertical change of $\chi(\omega, z)$ is given by eliminating $u$, $\mathrm{w}, \mathrm{p}$ and $\rho$ :

$$
\frac{\mathrm{d}^{2} \chi}{\mathrm{d} z^{2}}+\frac{1}{\mathrm{c}^{2}}\left(\frac{\mathrm{dc}}{\mathrm{d} z}-\gamma \mathrm{g}\right) \frac{\mathrm{d} x}{\mathrm{~d} z}+\left[\frac{\omega^{2}}{\mathrm{c}^{2}}-\mathrm{k}^{2}+\frac{\mathrm{g}^{2} \mathbf{k}^{2}}{\omega^{2} \mathrm{c}^{2}}\left(\frac{\mathrm{dc}}{\mathrm{dz}}+(\gamma-1) \mathrm{g}\right)\right] x=0
$$

Since $c^{2}=\gamma / \mathrm{H}$, this can be written as

$$
\frac{\mathrm{d}^{2} \chi}{\mathrm{dz}}+\frac{1}{\mathrm{H}}\left(\mathrm{H}^{\prime}-1\right) \frac{\mathrm{d} X}{\mathrm{dz}}+\left[\frac{\omega^{2}}{\gamma \mathrm{gH}}-\mathrm{k}^{2}+\frac{\mathrm{k}^{2} \mathrm{~g}^{2}}{\omega^{2} \mathrm{H}}\left(\mathrm{H}^{\prime}+1-\frac{1}{\gamma}\right)\right] x=0,
$$

where $\mathrm{H}^{\prime}=\mathrm{dH} / \mathrm{dz}$.

\section{The Diagnostic Diagram}

The wave equation (Equation 5) can be written

$$
\frac{d^{2} x}{d z^{2}}-2 N \frac{d x}{d z}+M^{2} X=0
$$

where

$$
\begin{gathered}
N=\frac{1}{2 H}\left(1-H^{\prime}\right), \\
M^{2}=\frac{\omega^{2}}{c^{2}}-k^{2}+\frac{k^{2} g}{\omega^{2} H}\left(H^{\prime}+1-\frac{1}{\gamma}\right)
\end{gathered}
$$

The solution of the differential equation (Equation 6 ) is given approximately by

$$
\chi(\omega, z)=e^{\mathrm{N} z}\left(\mathrm{Ae}^{-\mathrm{nz}}+\mathrm{Be}^{+\mathrm{nz}}\right),
$$

where $\mathrm{A}$ and $\mathrm{B}$ are constant and can be determined by boundary conditions. 
It should be noted that the solution (Equation 9) of Equations 5 or 6 can be classified into cellular and non-cellular types*, depending upon the relative magnitudes of $\mathrm{N}$ and $\mathrm{M}$, i.e.,

(i) cellular solution

$$
\mathrm{n}=\mathrm{i} \eta, \quad \eta^{2}=\mathrm{M}^{2}-\mathrm{N}^{2} \text { for } \mathrm{M}^{2}>\mathrm{N}^{2} \text {, }
$$

(ii) non-cellular solution

$$
n^{2}=N^{2}-M^{2} \text { for } N^{2}<M^{2} \text {. }
$$

The cellular waves have propagation vectors in both the horizontal $(k)$ and vertical $(\eta)$ directions, but non-cellular wave has no propagation vector in the vertical direction and simply propagates in the horizontal direction.

Since $M$ is a function of the horizontal wave number, $k$, Equation 10 gives the relation between two wave numbers in the vertical $(\eta)$ and the horizontal direction $(k)$ : Equation 10 is written as

$$
\frac{\eta^{2} c^{2}}{\omega^{2}-\omega_{A}^{2}}+\frac{k^{2} c^{2}\left(\omega^{2}-\omega_{B}^{2}\right)}{\omega^{2}-\omega_{A}^{2}}=1 \text {, }
$$

where

$$
\begin{gathered}
\omega_{A}^{2}=\left(\frac{\gamma_{B}}{2 c^{2}}\right)^{2}\left(1-\frac{1}{\gamma g} \frac{d c^{2}}{d z}\right)^{2} \text { or } \omega_{A}=\frac{c}{2 H}\left(1-H^{\prime}\right), \\
\omega_{B}^{2}=\frac{g}{c^{2}}\left(\frac{d c^{2}}{d z}+(\gamma-1) g\right) \text { or } \omega_{B}=\sqrt{B} \sqrt{\frac{H^{\prime}}{H}+\frac{1}{H}\left(1-\frac{1}{\gamma}\right)} ;
\end{gathered}
$$

$\omega_{\mathrm{A}}$ and $\omega_{\mathrm{B}}$ are called the critical acoustic angular frequency and the Brunt-Väisälä angular frequency. These are both functions of the atmospheric temperature distribution in the vertical direction and are related to the stability of layers in the atmosphere.

Since $\omega_{A}>\omega_{B}$ we can see from Equation 12 that, if $\omega>\omega_{A}$, the propagation surface is an ellipsoid while if $\omega<\omega_{B}$, it is an hyperboloid. In both cases, the rotation axis ( $z$-axis) is vertical (Figure 2). The waves corresponding to $\omega>\omega_{A}$ are called sonic or acoustic waves and the ones for $\omega<\omega_{B}$ are called thermobaric waves (Reference 19) or internal gravity waves (Reference 20) respectively.

Since $\eta^{2}$ becomes negative for $\omega_{B}<\omega<\omega_{A}$, no cellular wave exists for this frequency range. This situation can be seen from Figure 3, in which are plotted as a function of $k$ the two curves of $\omega$, corresponding to $\eta^{2}-n^{2}-0$. Similar curves are shown in Figure 4, where the wave period $(\tau$ in sec $)$ is *The nomenclature of cellular and non-cellular is taken from Martyn's paper (Reference 21) and this cortesponds to internal and external
waves discussed by Charney and Drazin (Reference 20). 


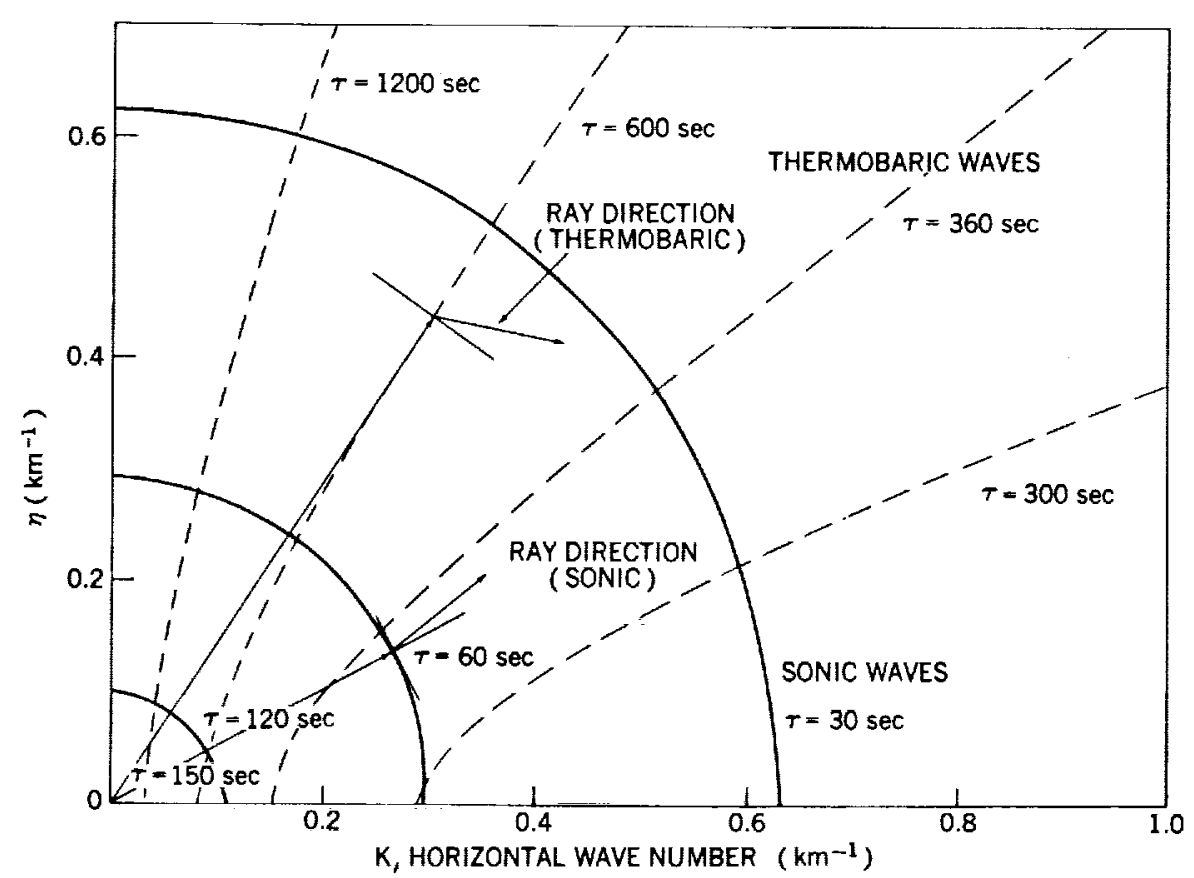

Figure 2-Propagation surfaces (lines) of internal atmospheric waves in the isothermal atmosphere with scale height $8 \mathrm{~km}\left(\mathrm{~T}=0^{\circ} \mathrm{K}\right)$, given by Equation 12; the solid and dashed lines correspond to sonic waves (acoustic waves) and thermobaric waves (internal gravity waves), respectively.

plotted against the horizontal wave length instead of $\omega$ and $\mathrm{k}$, respectively. $\tau_{A}$ and $\tau_{B}$ correspond to $\omega_{A}$ and $\omega_{B}$, respectively.

Figures 3 and 4 are called diagnostic diagrams of atmospheric waves (Reference 21), in which a domain indicated by $\mathrm{n}^{2}>0$ corresponds to the non-cellular mode while two domains $\mathrm{n}^{2}<0$ correspond to the cellular modes.

\section{APPROXIMATE TRANSMISSIVITY OF THE POLAR ATMOSPHERE}

Since the non-cellular (or external) waves, the period of which is limited between $\tau_{A}$ and $\tau_{B}$, have no vertical propagation vector, these waves neither contribute to the vertical energy transfer nor exist locally in free atmosphere.

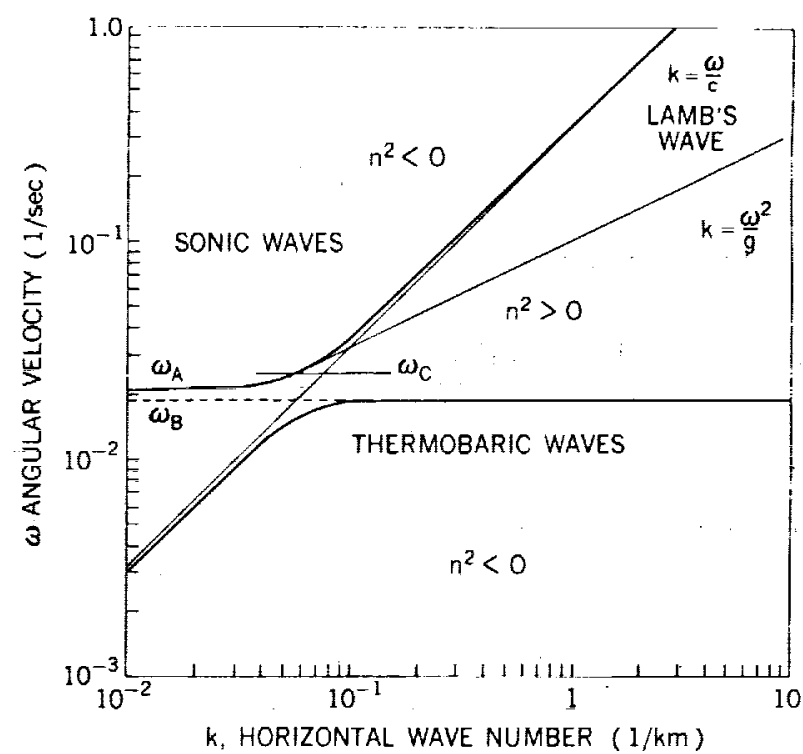

Figure 3-Diagnostic diagram of internal atmospheric waves in the isothermal atmosphere with scale height $8 \mathrm{~km}\left(\mathrm{~T}=0^{\circ} \mathrm{K}\right)$. 


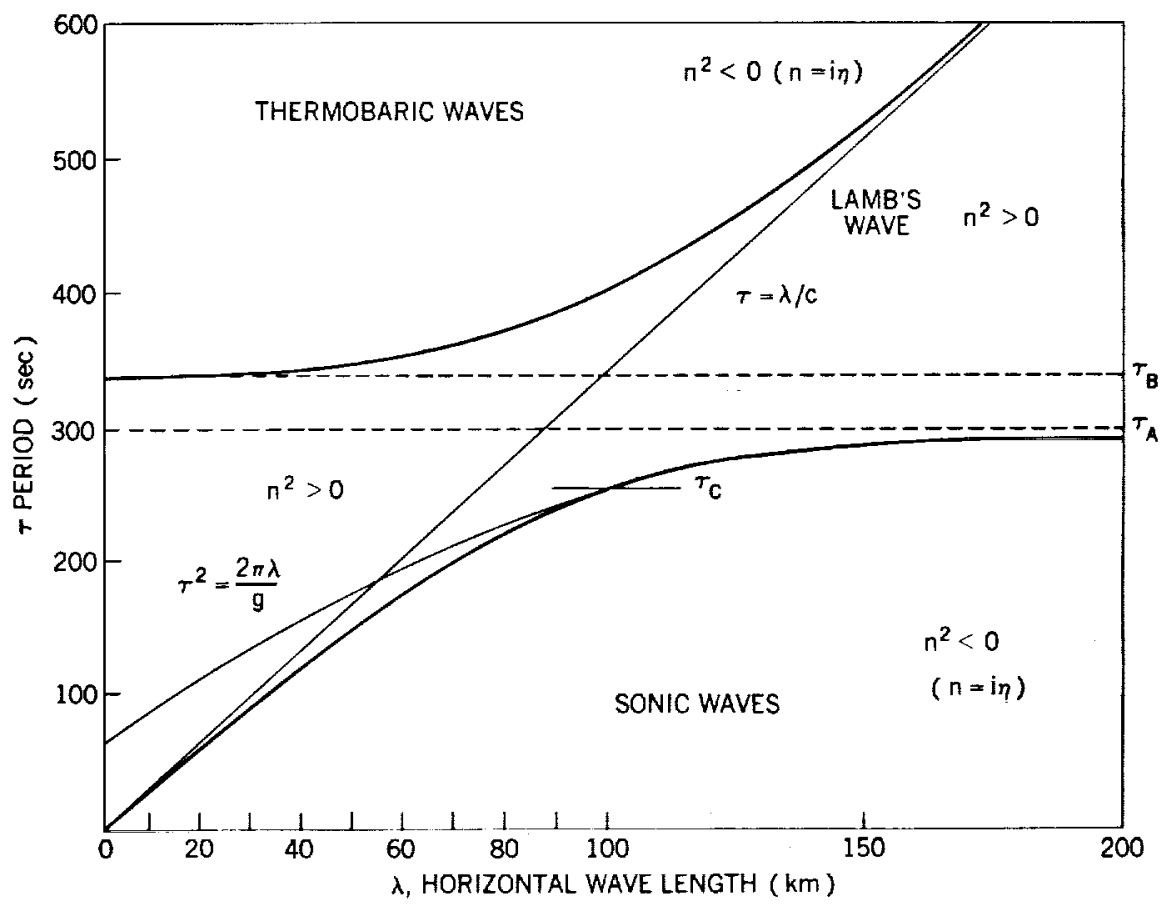

Figure 4-Diagnostic diagram of internal atmospheric waves in the isothermal atmosphere with scale height $8 \mathrm{~km}\left(T=0^{\circ} \mathrm{K}\right)$.

Among two kinds of cellular (or internal) waves, on the other hand, the thermobaric (or internal gravity) mode can propagate with larger periods than the Brunt period $\tau_{B}$, while the sonic (or acoustic) modes can exist only below a period $\tau_{A}$.

As can be seen from Equations 13 and 14, these two critical periods are a function of temperature and vertical temperature gradients in the atmosphere (i.e., the lapse rate of atmospheric temperature). Therefore, these values differ not only with height but also with season. In Figures 5 and 6 , $\tau_{A}$ and $\tau_{B}$ are plotted against altitude for polar atmospheres above Fort Churchill in summer and in winter, respectively.

The atmospheric models of the two seasons are essentially the same as the ones reported by Stroud et al. (Reference 22; see also Figure 13, Reference 23 and Figure 1, Reference 2). In a domain between two critical periods, i.e., $\tau_{\mathbf{A}}$ (solid curves) and $\tau_{\mathbf{B}}$ (dashed curves), only the noncellular mode can exist. In other words, this is a forbidden region for both acoustic and thermobaric modes of internal atmospheric waves. Therefore, we can see that no thermobaric waves with periods shorter than $370 \mathrm{sec}$ can propagate across the $50-\mathrm{km}$ level and that no sonic waves with periods Ionger than $250 \mathrm{sec}$ can propagate through the layer around $80 \mathrm{~km}$ in summertime. But in winter both waves are able to propagate through these layers and the critical period for each approaches $320 \mathrm{sec}$ for thermobaric waves and $290 \mathrm{sec}$ for sonic waves, respectively.

To see the transparency (or transmissivity) of the atmosphere for internal atmospheric waves more quantitatively, the wave equation (Equation 5 or 6 ) should be transformed into a more simple 


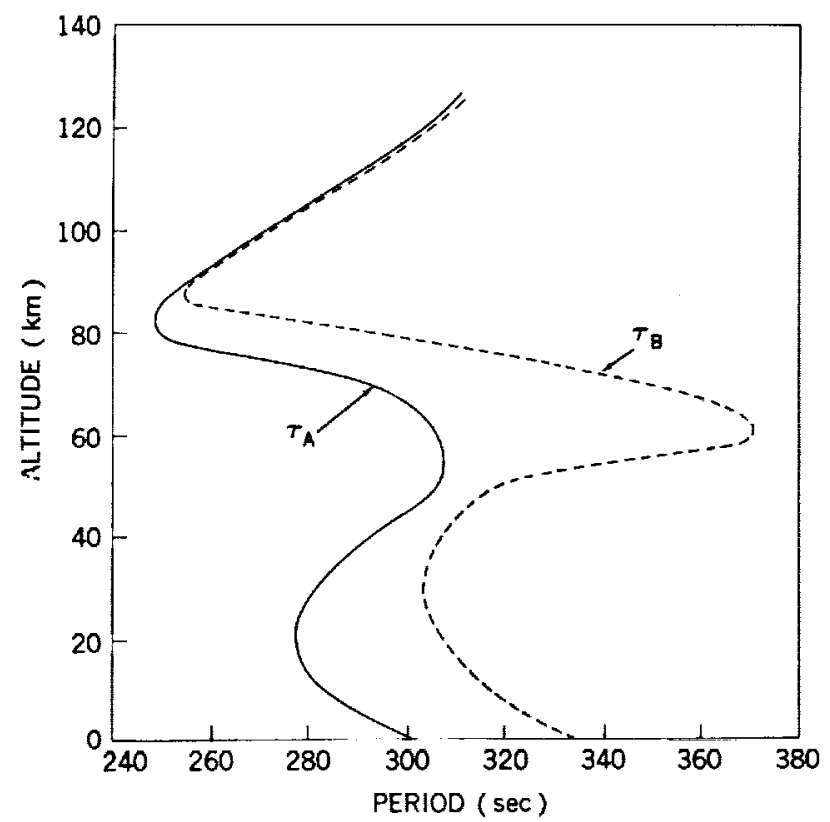

Figure 5-Critical acoustic period, $\tau_{A}$, and BruntVäisälä period, $\tau_{B}$, as a function of altitude for the summer polor atmosphere.

form. By substituting

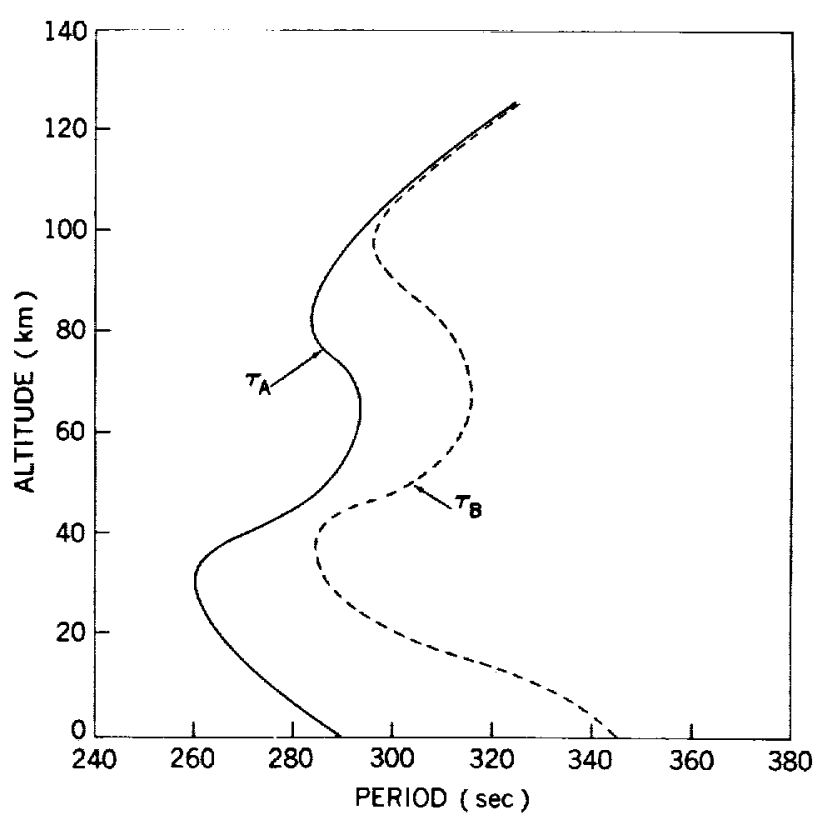

Figure 6-Critical acoustic period, $\tau_{A}$, and BruntVaisälä period, $\tau_{B}$, as a function of altitude for the winter polar atmosphere.

$$
y=\int_{z_{0}}^{x} \frac{d z}{H}
$$

and

$$
\chi(z)=c^{y / 2} \phi(y)
$$

the term $\mathrm{d}_{\chi} \mathrm{dz}$ in the wave equation can be eliminated; then Equation 6 can be written as

$$
\frac{d^{2} \phi(y)}{d y^{2}}=-K^{2} \phi(y)
$$

where

$$
\mathrm{K}^{2}=\eta^{2} \cdot \mathrm{H}^{2}
$$

As can be seen from Equations 7, 8, and 10, $\eta^{2}$ is a function of $\sigma, k, H$, and $H^{\prime}(=d H / d z)$. 


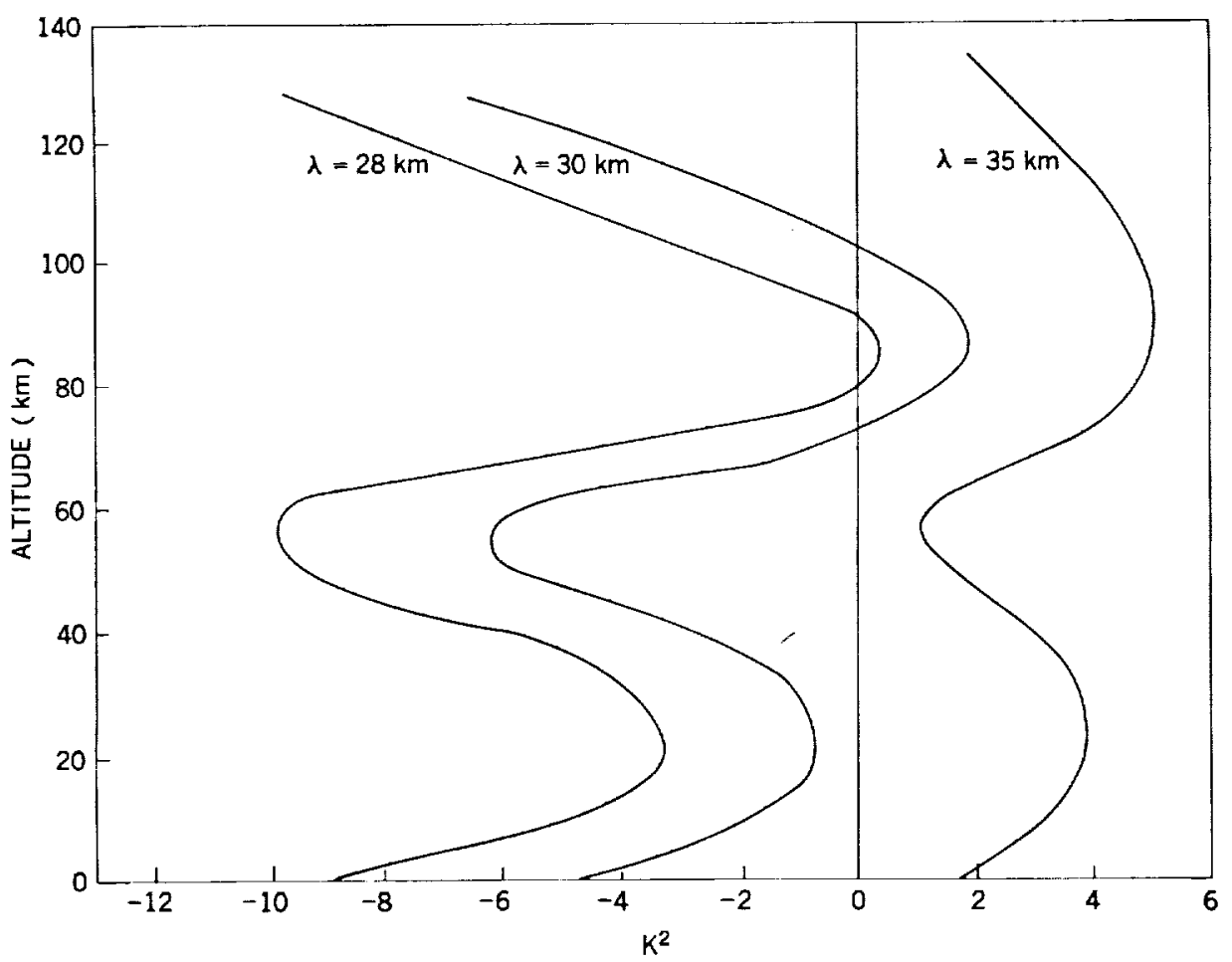

(a) $\tau=100 \mathrm{sec}$.

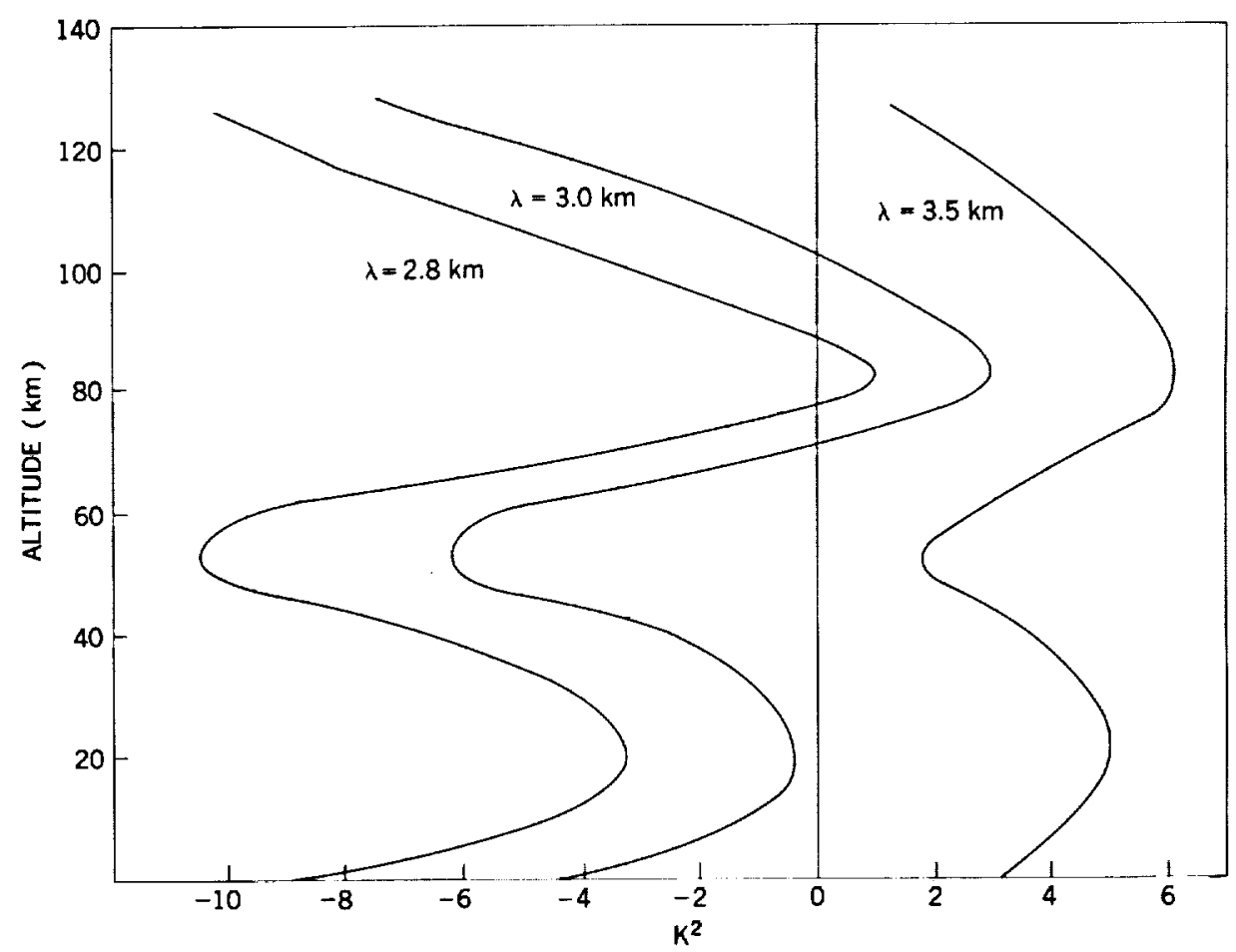

(b) $\tau=10 \mathrm{sec}$.

Figure 7-Square of the index of refraction, $\mathrm{K}^{2}$, for atmospheric acoustic waves with period $\tau$ in the summertime polar atmosphere as a function of height, where the parameter $\lambda$ is the horizontal wave length in $\mathrm{km}$. 


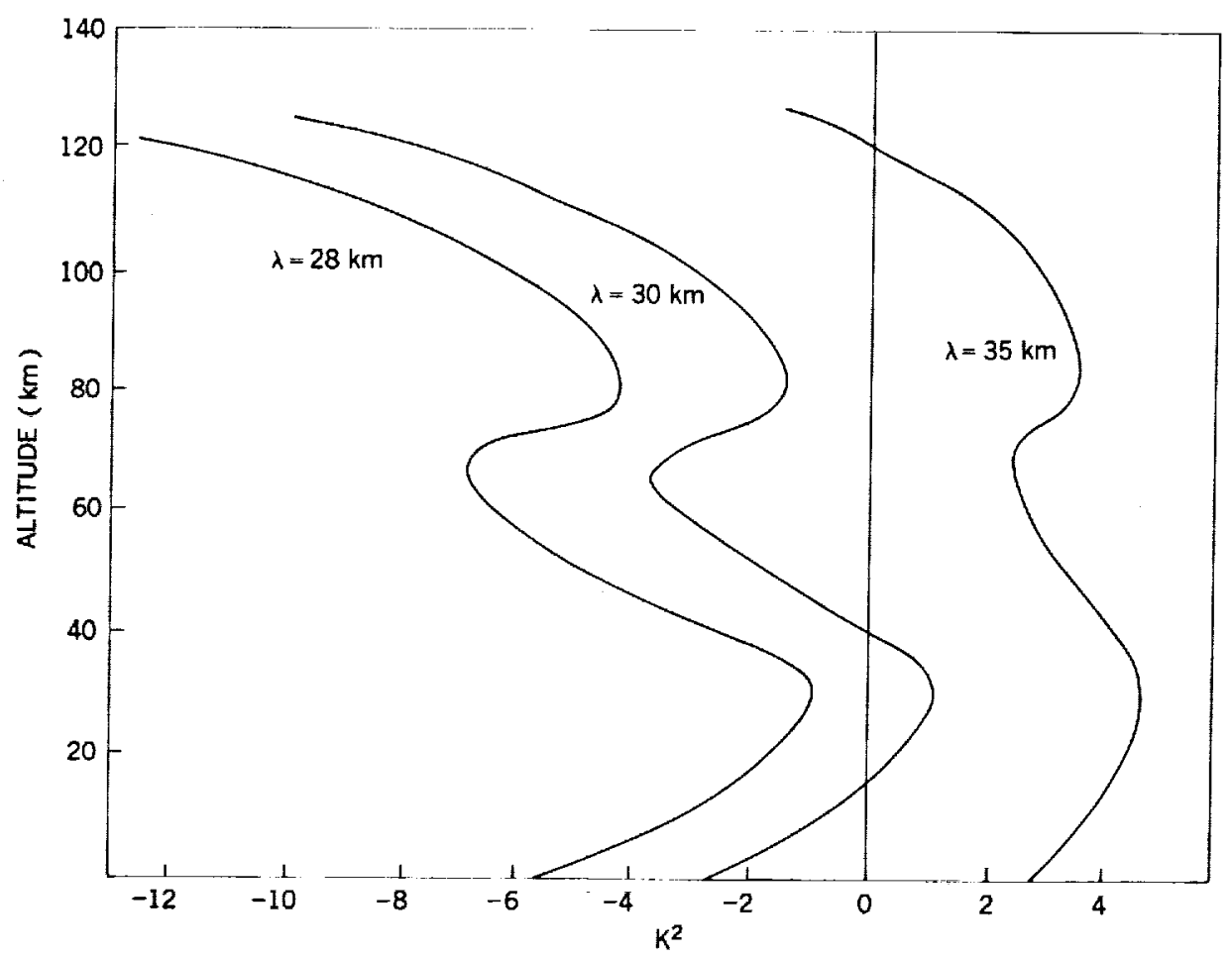

(a) $\tau=100 \mathrm{sec}$.

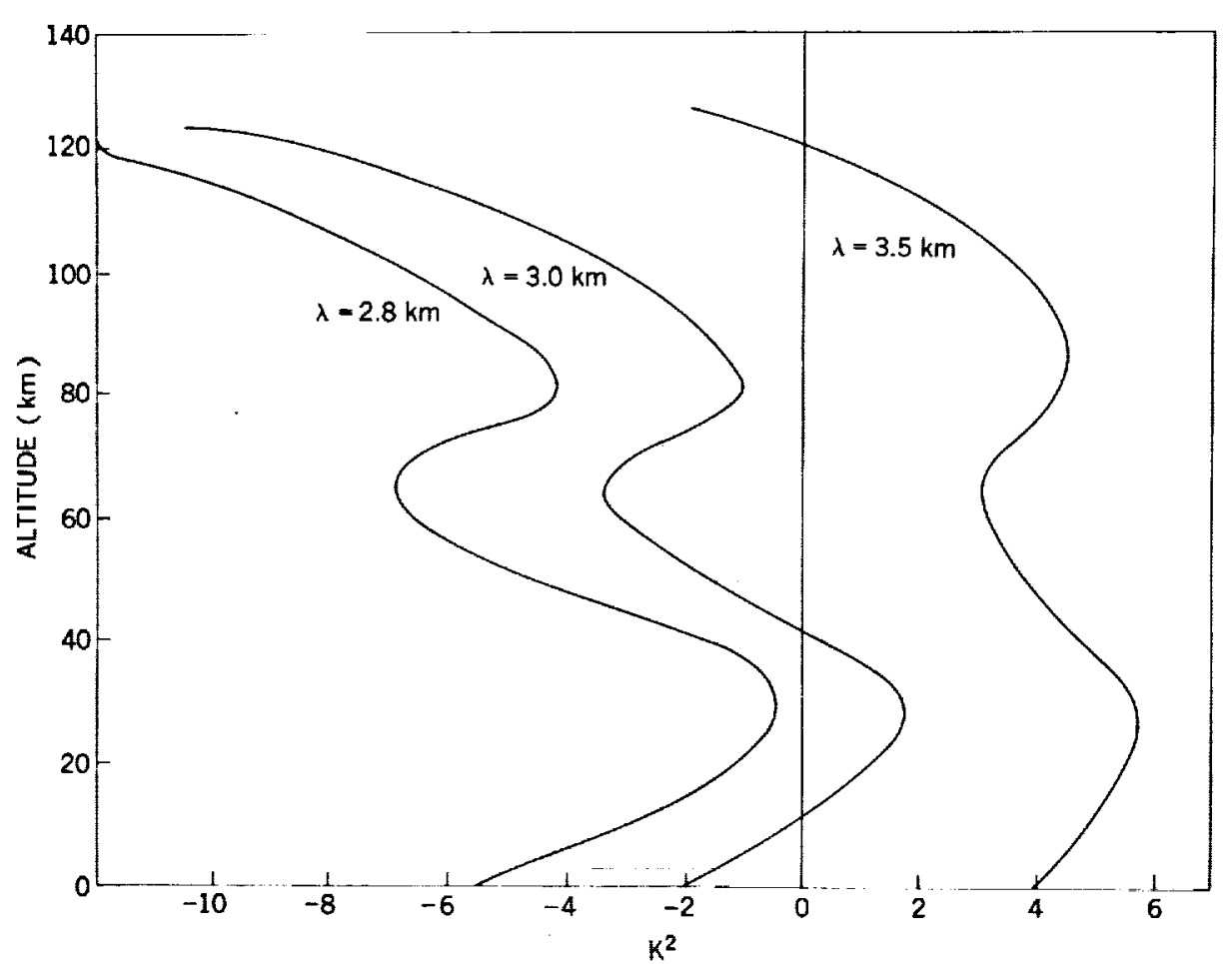

(b) $\tau=10 \mathrm{sec}$,

Figure 8-Curves similar to Figure 7 for wintertime polar atmosphere. 
The one-dimensional wave equation (Equation 15) indicates that, if $\mathrm{K}^{2}>0$, the solution $\phi(\mathrm{y})$ has a wave nature and the corresponding waves can propagate along the $y$-axis ( $z$-axis vertical direction) within the domain, where this condition is satisfied. On the other hand, if $K^{2} \leq 0$ ( $K$ is imaginary) i.e., no internal wave exists and vertical propagation of waves is inhibited by the barrier, where $\mathrm{K}^{2}$ becomes negative. Thus, the propagation of internal waves is limited within regions where $\mathrm{K}$ is real.

For the acoustic mode of atmospheric waves with periods $100 \mathrm{sec}$ and $10 \mathrm{sec}, \mathrm{K}^{2}$ is plotted against $z$ in Figures $7 \mathrm{a}$ and $7 \mathrm{~b}$ for summertime and in Figures $8 \mathrm{a}$ and $8 \mathrm{~b}$ for wintertime, respectively. In these figures, the horizontal wavelength is taken as a parameter.

Since $\lambda=2 \pi / k$, where $k$ is a wave number in the horizontal direction, there is a shortest (critical) horizontal wavelength $\lambda_{c}$ for a given period of the waves, corresponding to a largest horizontal wave number $k_{c}$. From Figures 7 and 8, we can see that the waves propagating close to the vertical axis can propagate upwards as far as $\tau<\tau_{A}$, while the waves propagating in an oblique direction meet a barrier where $\mathrm{K}^{2}$ becomes negative even if the condition $\tau \tau_{A}$ is satisfied. If there are more than two barriers, those obliquely propagating waves are trapped between these barriers, forming the "duct" in the horizontal direction. It should be noted from Figure 2 that $\mathbf{k}=0$ (i.e. $\lambda=\infty$ ) represents the wave propagation in the vertical direction.

Using the diagram shown in Figure 2 for the conditions at each level, the critical angle $\theta_{c}$ can be drawn as a function of altitude for a given period, $\tau$, of the waves, provided that $\tau<\tau_{A^{*}}$ The angle $\theta_{c}$ is defined such that the waves propagating obliquely with zenith angle larger than $\theta_{c}$ cannot enter into the above layer, simply because $\mathrm{K}^{2}$ becomes negative beyond this angle. In other words, $\theta_{\mathrm{c}}$ can be regarded as the aperture of the allowed cone around the vertical axis at each level in the atmosphere. Therefore, the relative transmissivity, $f_{t}(\tau, z)$, of each layer for vertical propagation of the atmospheric acoustic wave is approximately given by $\left(\theta_{c} / \pi / 2\right)^{2}$, provided that $\theta_{c}$ is expressed in radians. In Figure 9, $f_{t}(\tau, z)$ is shown for the wave with a 100 sec period normalized to the condition at $25 \mathrm{~km}$. Similar curves are obtainable for any waves with $\tau<\tau_{A}$. From Figure 9, we can see that the atmosphere above mesopause, which is nearly $80 \mathrm{~km}$ in polar regions, is always opaque for atmospheric acoustic waves.

It should be noted that the wind system in the higher layers does not effect $f_{t}(\tau, z)$ very much, because an oblique axis tilted windward direction can be regarded as the direction of maximum propagation.

\section{UPWARD ENERGY TRANSFER BY PRESSURE WAVES}

\section{Acoustic Waves Generated Aerodynamically in the}

Sound waves generated aerodynamically are distinct from sound produced by the vibration of solids. A strong jet flow in the free atmosphere produces sound waves due to turbulent motions in the boundary layers between the core of the jet and the surrounding air. Lighthill (References 24 and 25) investigated this problem and derived a theoretical expression of the power of sound waves as a function 
of the jet stream velocity. His theory was further extended by Proudman (Reference 26) to the generation of sonic waves by isotropic turbulence.

Although the acoustic heating of the solar corona is discussed by Schatzman (Reference 27), similar calculations cannot be applied to the earth's atmosphere, because the situation there is entirely different from that of solar atmosphere. In the earth's upper atmosphere, the effect of magnetic fields on the generation of sound noise by isotropic turbulence (Reference 28) is important as well as their effect on the dissipation processes as in the case of solar corona.

Since the aerodynamical production of acoustic waves has been developed in detail by Lighthill and Proudman, only their results will be given, and, in turn, applied to the present problem in the earth's upper atmosphere.

The acoustic power output per unit mass of air $P$, in ergs/gm-sec, is given by

$$
P=a \in M^{5} \quad \text { for } M \ll 1
$$

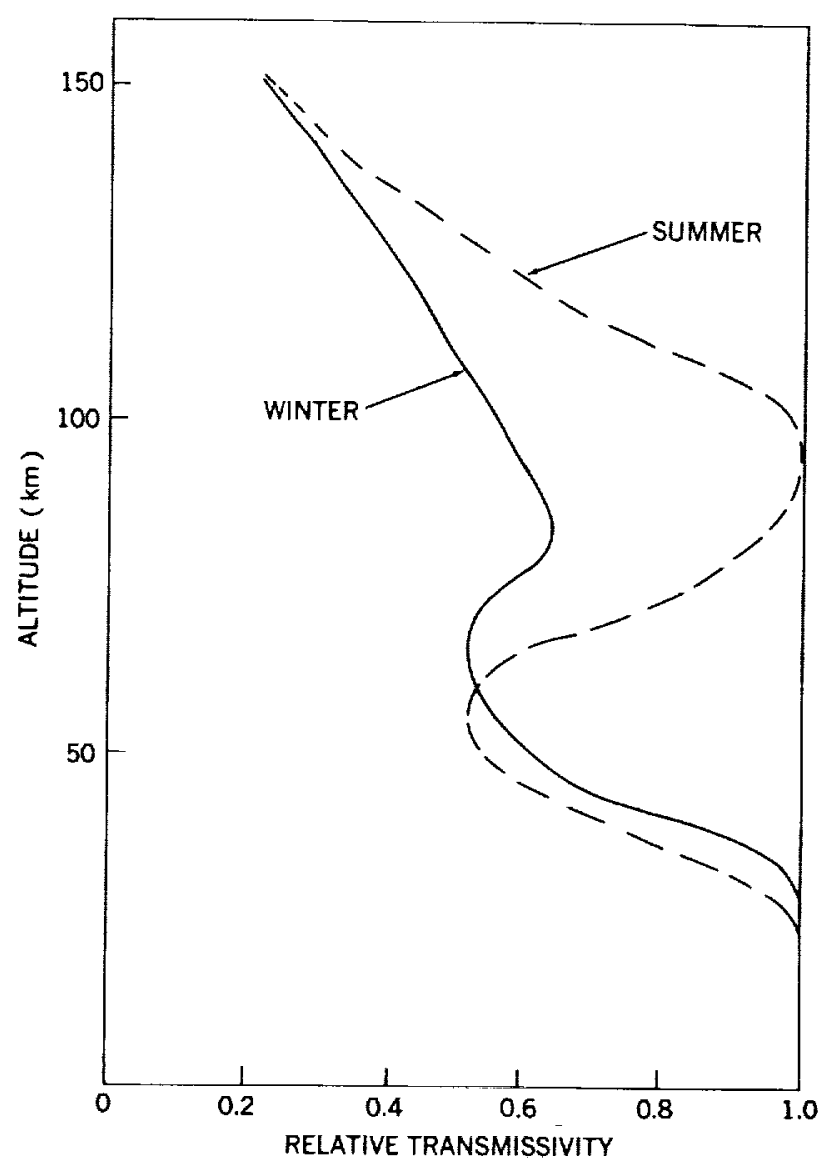

Figure 9-Relative transmissivity of the polar atmosphere, $f,(\tau, z)$ for atmospheric acoustic waves with a period $\tau=100 \mathrm{sec}$. The solid and dashed lines correspond to wintertime and summertime, respectively.

where $a$ is a nondimensional constant, $M$ is Mach number $\epsilon$ is the mean rate of energy dissipation per unit mass.

According to Batchelor (Reference 29, p. 103), $\epsilon$ is given by

$$
\epsilon\left(\approx \frac{3}{2} \frac{\mathrm{du}^{2}}{\mathrm{dt}}\right)=A \frac{\overline{\mathrm{u}}^{3}}{\mathrm{l}},
$$

where $\mathrm{A}$ is a nondimensional constant, which is of the order of unity-about $1.8, l$ a characteristic length which can be taken as the reciprocal of the wave number at which the maximum of the energy spectrum occurs, and $u$ the root mean square velocity of the turbulence. 
If the "double correlation function" given by Heisenberg (Reference 30 ) is correct, the constant $a$ in Equation 16 has the value 38. Therefore Equation 16 is

$$
P=70 \frac{\overline{\mathrm{u}}^{3}}{l} \cdot(\mathrm{M})^{5}
$$

where $M=u / c, u$ and $c$ are the mean velocity of jet flow and the sound velocity respectively.

In the upper atmosphere, where the Reynolds number is very large, the spectrum of turbulence consists generally of the following ranges:

1. The energy-producing range, which contains large eddies,

2. The inertial subrange in which energy is neither created nor destroyed; and

3. The energy-dissipating range, which contains small eddies.

As pointed out by Proudman (Reference 26), the turbulence which makes an appreciable contribution to the generation of sonic waves at large Reynolds numbers belongs to the eddies that do not dissipate energy. In other words, the main source of aerodynamically produced sonic waves is turbulent motion around the jet flow; this turbulence belongs to (1) energy producing range, and to (2) inertial sub-range. Therefore, following Batchelor (Reference 29, Chap. 7), we can assume

$$
10^{3} \leqslant l \leqslant 10^{4}
$$

and

$$
\frac{1}{10} \lesssim \frac{\bar{u}}{u} \lesssim \frac{1}{3}
$$

Distribution of turbulence along the jet stream can be assumed uniform, then the acoustic output per unit area along the jet (in $\mathrm{erg} / \mathrm{cm}^{2}-\mathrm{sec}$ ) will be

$$
7 \cdot 10^{-6} u^{3} M^{5} \rho_{0} \lesssim I(u) \lesssim 3 \cdot 10^{-3} u^{3} M^{5} \rho_{0}
$$

where $\rho_{0}$ is the mean density of air around the source. In Equation 17, $u$ is in $\mathrm{cm} / \mathrm{sec}$. The acoustic output $I(u)$ is shown in Figure 10, assuming the height of the source to be $25 \mathrm{~km}$.

From this figure we can see that the production of sonic waves decreases drastically below a wind velocity of the order of $50 \mathrm{~m} / \mathrm{sec}$. Since the derivation of Equation 17 is based on the assumption that Mach number is small (Reference 25), the output power beyond $u=150 \mathrm{~m} / \mathrm{sec}$ might be incor rect. 


\section{Attenuation of Atmospheric Waves}

Any atmospheric wave is attenuated in air by the following effects:

1. friction due to the viscosity of air,

2. thermal conduction of air,

3. radiation through the atmosphere,

4. dispersion due to the inhomogenity of air in the atmosphere.

As was shown by Rayleigh (Reference 31 ), effects of radiation and dispersion are generally small for the acoustic waves as compared with the effects of friction and thermal conduction.

Consideration of these effects leads to the so-called classical Stokes-Kirchhoff formula for the attenuation coefficient $a(\tau)$ (Reference 31), which is given by

$$
a(\tau)=\frac{4 \pi^{2}}{\tau^{2} c^{3}}\left[\frac{\gamma-1}{\gamma} a^{2}+\frac{4}{3} \nu\right],
$$

where $\alpha^{2}$ and $v$ are the coefficients of thermal conductivity and kinematic viscosity of air:

$$
a^{2}=\frac{\kappa}{c_{p} p}
$$

and

$$
\nu=\frac{\mu}{\rho}
$$

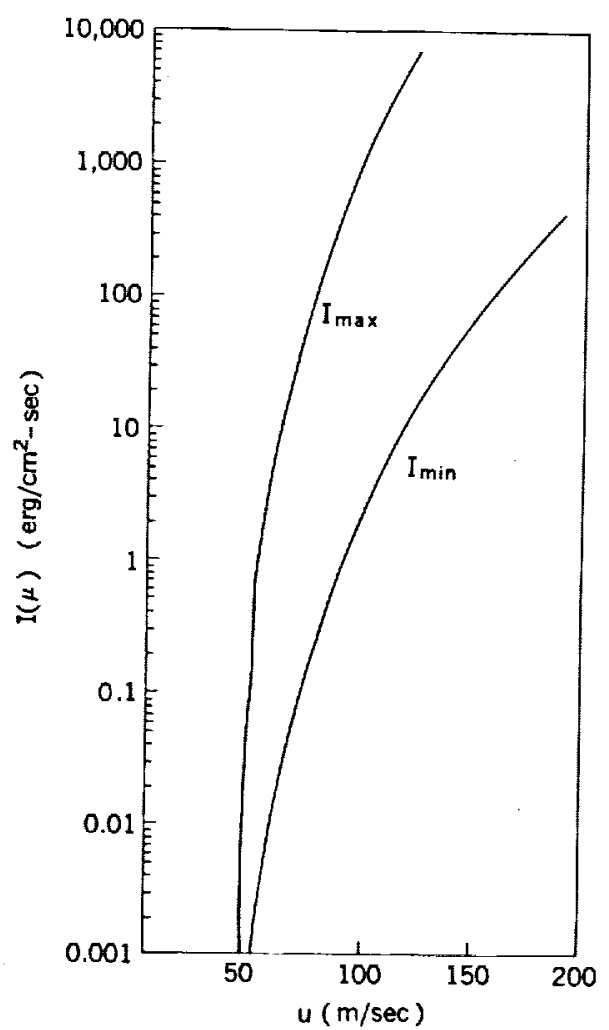

Figure 10-Acoustic output power of the polar stratosphere, I(u), plotted against the mean wind velocity of the jet stream, $u$.

The heat conductivity of air, ${ }^{*}$, is the order of $6 \times 10^{-6} \mathrm{cal} / \mathrm{cm}-\mathrm{sec}^{\circ} \mathrm{K}$ at NTP; and the specific heat $C_{p}$ is nearly $0.27 \mathrm{cal} / \mathrm{gm}^{\circ} \mathrm{K}$ below the mesopause and increases with height to $0.3 \mathrm{cal} / \mathrm{gm}^{\circ} \mathrm{K}$ above $350 \mathrm{~km}$ approximately (Reference 32 ).

The viscosity of air, $\mu$, is of the order of $1.7 \times 10^{-4}$ poise at NTP. Using these numerical values, the attenuation coefficient (Equation 18) becomes

$$
\alpha(\tau)=\frac{2.4 \times 10^{-16}}{\rho \tau^{2}}
$$


As was shown by Golitsyn (Reference 33 ), the long period pressure wave undergoes an additional dissipation owing to the Joule-loss of the current induced by fluctuations of the conducting medium of ionosphere in the earth's magnetic field.

In Figure 11, the attenuation factor

$$
\mathrm{f}_{\mathrm{a}}(\tau, z)=\exp \left[-\int_{0}^{z} \alpha\left(\tau, z^{\prime}\right) \mathrm{d} \mathrm{z}^{\prime}\right]
$$

is shown for four different periods of waves $(1,10,30$ and $100 \mathrm{sec})$. The dashed lines in Figure 11 are taken from Golitsyn's results, which took account of the Joule loss (Reference 33).

An estimate of the rate of energy dissipation per unit time per unit thickness per unit cross section in the upper atmosphere, $\mathrm{dE}_{\mathrm{t}} / \mathrm{dz}$ in $\mathrm{erg} / \mathrm{cm}^{3}-\mathrm{sec}$, is made by the following approximation:

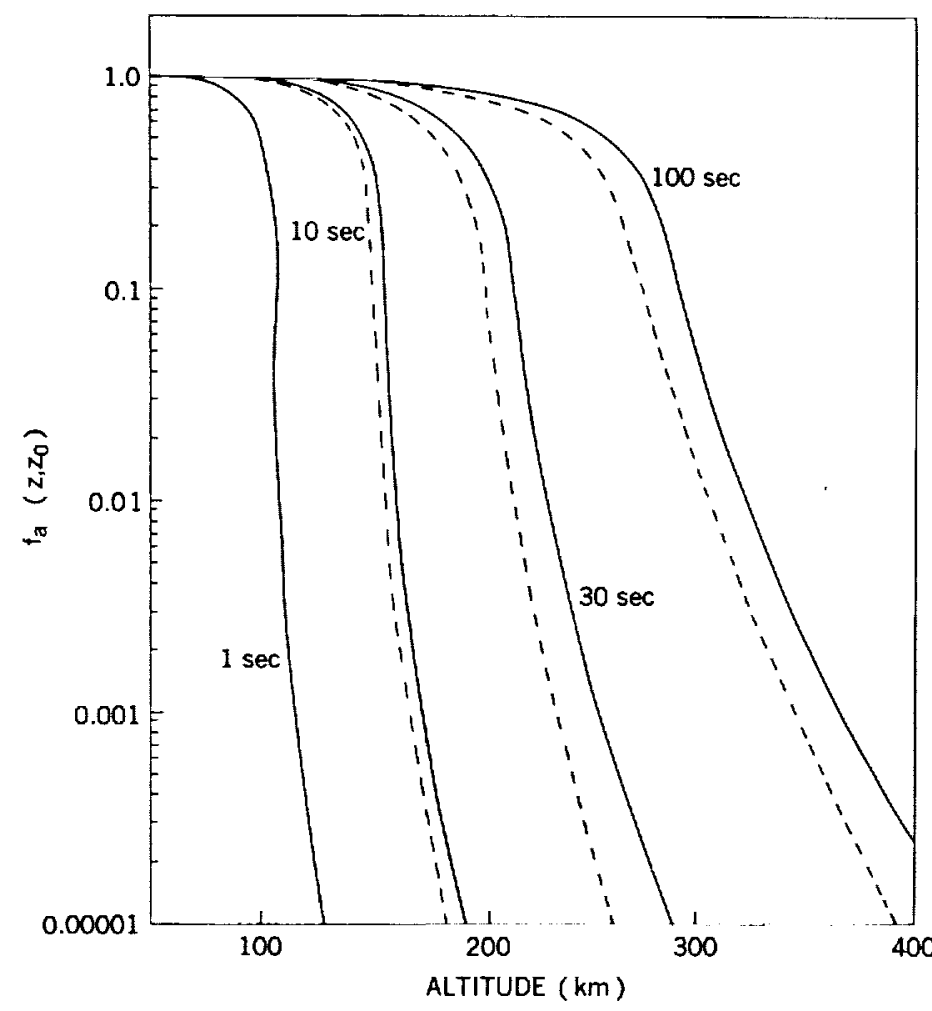

Figure 11-Attenuation factor, $f(\tau, z)$, of atmospheric acoustic wave versus altitude, $z$ for $\tau=1,10,30$ and $100 \mathrm{sec}$. The solid lines are calculated by the classical formula and the dashed lines are given by Golitsyn, with the Joule loss in the ionosphere taken into account.

$$
\frac{d E_{t}}{d z}=\int_{\omega_{A}(z)}^{\infty} i(\omega) f_{t}(\omega, z) \frac{d}{d z} f_{a}(\omega, z) d \omega
$$

where

$\mathrm{f}_{\mathrm{a}}(\omega, z)$, the attenuation factor, is given by Equation 19 and shown in Figure 11;

$\mathrm{f}_{\mathrm{t}}(\omega, z)$ is the relative transmissivity of atmosphere for the wave with angular frequency $\omega$ at the altitude $z$, which is shown, for example, in Figure 9 for $\tau=(2 \pi / \omega)=100$ sec; and

$i(\omega)$ is the differential frequency spectrum of the wave, which will be assumed to be

$$
i(\omega)=i_{0} \omega^{-m} \quad m>1 .
$$


From Figures 5 and 6, the lower limit $\omega_{A}$ of the integral in Equation 20 can be taken as follows:

(i) summer

$\begin{array}{rlr}\omega_{A}=\omega_{A}(z) & \text { for } & 0 \leq z<20 \mathrm{~km}, \\ 0.023 & \text { for } & 20 \leq z<70 \mathrm{~km}, \\ \omega_{A}(z) & \text { for } & 70 \leq z<85 \mathrm{~km}, \\ 0.025 & \text { for } & z \geq 85 \mathrm{~km}\end{array}$

(ii) winter

$\begin{aligned} \omega_{\mathrm{A}}=\omega_{\mathrm{A}}(\mathrm{z}) & \text { for } & 0 \leq z<30 \mathrm{~km}, \\ \mathbf{0 . 0 2 4} & \text { for } & z \geq 30 \mathrm{~km} .\end{aligned}$

From this figure, we can see that the change of $\omega_{A}$ with height is small. Thus, $\omega_{A}$ is taken as a constant value $(0.024)$ for both seasons.

Strictly speaking, the right hand side of Equation 20 should be multiplied by a geometrical factor, which is inversely proportional to the distance from the source. The width of the source-the polar night jet stream-is more than several hundred kilometers (Reference 18) and the boundary is widely diffused horizontally. In this respect, the geometric attenuation factor is not important and can be neglected in the present approximation.

Since the waves are propagating upwards, $\mathrm{f}_{\mathrm{t}}(\omega, z)$ in the integrand of Equation 20 may be taken as a constant value above the minimum transmissivity level. However, the formation of wave-ducts is highly probable above this or between those levels of minimum transmissivity, for example, between 30 and $70 \mathrm{~km}$ in summer (see Figure 5). As can be seen from the result, the choice of $f_{t}(\omega, z)$ above the minimum transmissivity level (if it is constant or variable as shown in Figure 9, for example), does not affect the present calculation very much.

A constant $i_{0}$ in Equation 21 is given by

$$
I_{0}=\int_{\omega_{A}\left(z_{0}\right)}^{\infty} i_{0} \omega^{-m} d \sigma=i_{0} \frac{\omega_{A}^{m-1}}{m-1}
$$

where $I_{0}=I_{0}(u)$ is the output power of the acoustic wave at the level of the source, $z_{0}$, given by Equation 17 and shown in Figure 10.

In Figure 12, the relative dissipation rate of energy $\left(d E_{t} / d z\right) / I_{0}$ is plotted against altitude $z$ for two cases of the spectrum, $m=2$ (heavy lines) and $m=5$ (light lines). The solid and dashed lines correspond to the wintertime and the summertime polar atmosphere, respectively. The two curves in the upper portion of Figure 12 are calculated by neglecting the transmissivity of the atmosphere, i.e. 


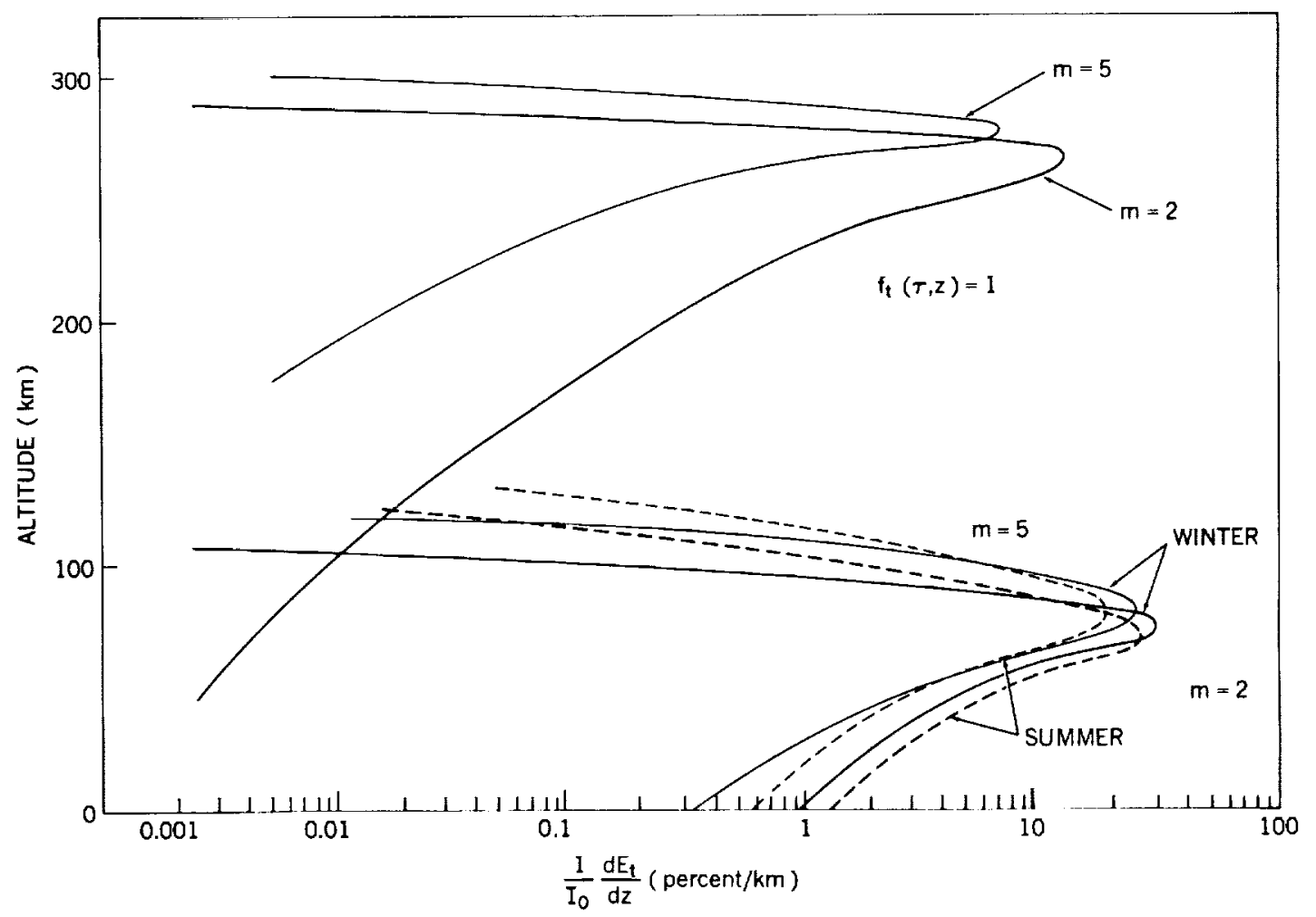

Figure 12-Relative dissipation rate of energy flux transferred by atmospheric acoustic waves, where $\mathrm{I}_{0}=\mathrm{I}_{0}(\mathrm{u})$ is the acoustic output at the source as shown in Figure 10. Solid and dashed lines correspond to wintertime and summertime polar armospheres, respectively; heavy and light lines stand for the hard spectrum $(m=2)$ and soft spectrum $(m=5)$ of the waves, respectively.

$f_{t}(\omega, z)$ is assumed to be unity. The latter corresponds to the estimation made by Golitsyn (Reference 14).

If all those dissipated energies of acoustic pressure waves are assumed to be converted into thermal energy of the air, the rate of heating at each level, $\mathrm{dT}(\mathrm{z}) / \mathrm{dt}$ in ${ }^{\circ} \mathrm{C} / \mathrm{sec}$, is given by

$$
\frac{d T}{d t}=\frac{1}{C_{p} \rho(z)} \cdot \frac{1}{J_{0}} \frac{d E_{t}}{d z}
$$

where $J_{0}$ is Joule's mechanical equivalent of heat, $4.2 \times 10^{7} \mathrm{ergs} / \mathrm{cal} ; \mathrm{C}_{\mathrm{p}}$ is the specific heat of air at constant pressure, $\sim 0.3 \mathrm{cal} / \mathrm{gm}^{\circ} \mathrm{C}$; and $\rho(\mathrm{z})$ is the mean atmospheric density at the altitude $z$.

The results are shown in Figure 13, which corresponds to Figure 12 for a unit output power source. Since the latter is shown in Figure 10, the following points may be observed:

If the wind velocity around $25 \mathrm{~km}$ level is of the order of $30 \mathrm{~m} / \mathrm{sec}$, as in the usual summertime polar stratosphere, we can see that the acoustic power at the source is less than the order of $10^{-5}$ $\mathrm{erg} / \mathrm{cm}^{2}-\mathrm{sec}$ (from Figure 10). Then rate of maximum heating, dT/dz is, from Figure 13, of the order 


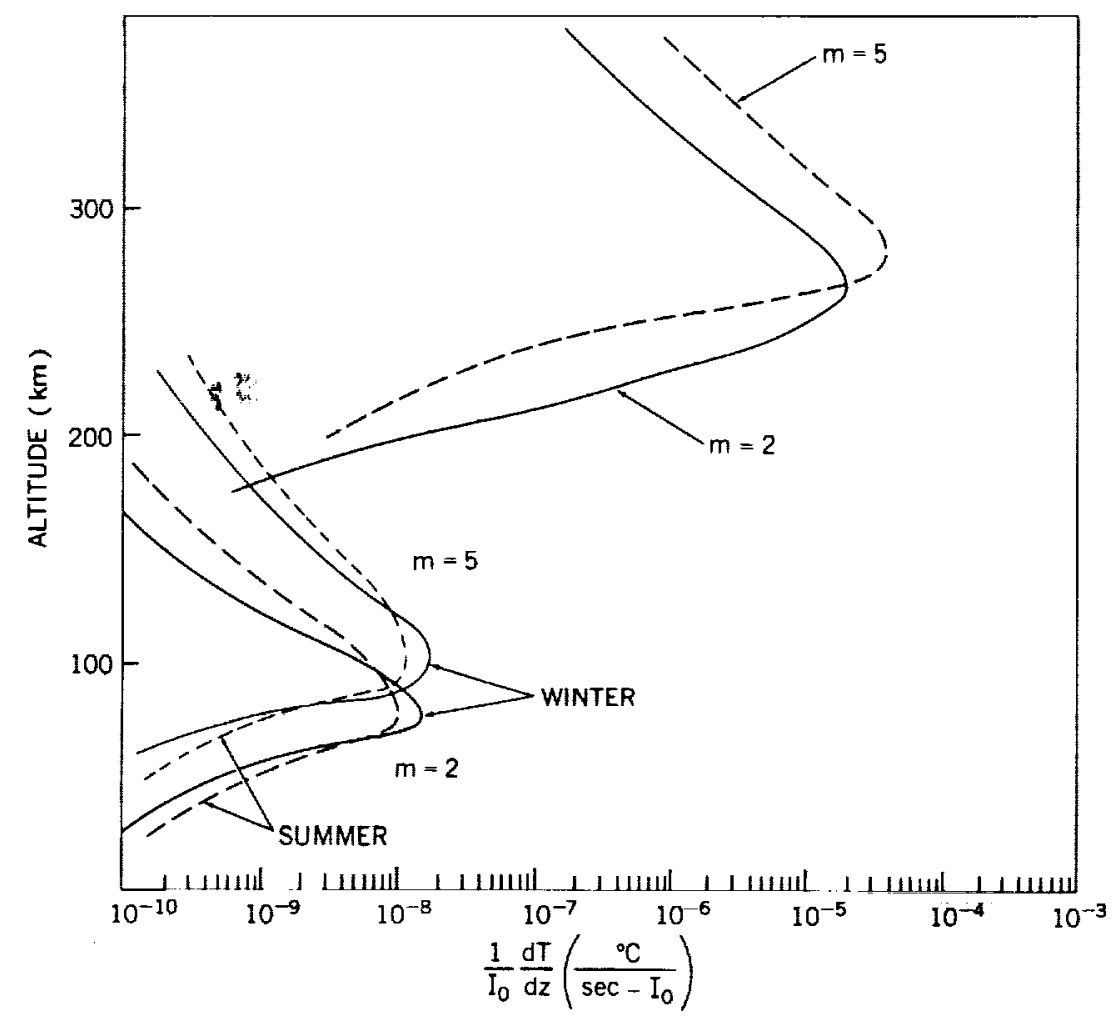

Figure 13-The rate of atmospheric heating in each layer due to the dissipation of acoustic energy flux I $\left(\mathrm{erg} / \mathrm{cm}^{2} \mathrm{sec}\right)$ versus altitude $z$. The lines are defined as in Figure 12.

of $10^{-8} \times 10^{-5}{ }^{\circ} \mathrm{C} / \mathrm{sec}$ or $10^{-8}{ }^{\circ} \mathrm{C} /$ day at the maximum, which height is around $75 \mathrm{~km}$ if the wave spectrum is hard $(m=2)$, or $100 \mathrm{~km}$ if the spectrum is soft $(\mathrm{m}=5)$, respectively.

On the other hand, if the wind velocity around $25 \mathrm{~km}$ exceeds $100 \mathrm{~m} / \mathrm{sec}$, which is steadily observed in the polar night jet stream (References 17 and 34 ), the output power $I_{0}$ is somewhere between $10^{3}$ and $1 \mathrm{erg} / \mathrm{cm}^{2} \mathrm{sec}$ (Figure 10). The corresponding maximum warming rate is, then $2 \times\left(10^{-5}\right.$ to $\left.10^{-8}\right){ }^{\circ} \mathrm{C} / \mathrm{sec}$ or $2 \times\left(1\right.$ to $\left.10^{-3}\right){ }^{\circ} \mathrm{C} /$ day at the altitude of $75 \mathrm{~km}$ for $\mathrm{m}=2$, or around 100 $\mathrm{km}$ for $\mathrm{m}=5$.

If the transmissivity of the atmosphere is disregarded, as in Golitsyn's estimation, then from the two upper curves shown in Figure 13, the rate of maximum heating is of the order of $10^{-10}{ }^{\circ} \mathrm{C} / \mathrm{sec}$ $\left(10^{-5}{ }^{\circ} \mathrm{C} / \mathrm{day}\right)$ in summer, and $10^{-2}$ to $10^{-5}\left(10^{3}\right.$ to $1^{\circ} \mathrm{C} /$ day $)$ in winter. The height of maximum heating is around 260 to $300 \mathrm{~km}$ which corresponds to $\mathrm{m}=2$ to 5 .

\section{CONCLUSION}

Although the estimated acoustic energy flux available for upper air heating has a wide range as shown in Figure 10 - due to ambiguities of several parameters such as the mean velocity of turbulent motion around the jet stream, $\bar{u}$; the effective size of eddy in this turbulence, $l$; and the frequency spectrum of the turbulence, the following remarks can be made from the present calculation. 
Because of the temperature gradient, the atmosphere above the $100 \mathrm{~km}$ level is not transparent for atmospheric acoustic waves - especially for long waves. Therefore, acoustic heating is most effective for warming around the $100 \mathrm{~km}$ level rather than the 200 to $300 \mathrm{~km}$ levels (Figure 13).

On the other hand, if the transmissivity of sound waves due to thermal gradient in the atmosphere is disregarded, most heating takes place around the $300 \mathrm{~km}$ level and its rate exceeds $10{ }^{\circ} \mathrm{C} /$ day in winter.

Although acoustic power from the polar night jet stream is more than two orders of magnitude larger than that of the tropospheric disturbance, which is of the order of $10^{-2} \mathrm{ergs} / \mathrm{cm}^{2} \mathrm{sec}$ (Reference 14), acoustic heating around the mesopause is not sufficient to compensate for the cooling rate (about $10^{\circ} \mathrm{C} /$ day) of these levels in winter.

In this respect, another mechanism of dynamical heating such as energy transfer by means of internal gravity waves (Reference 8 ) might be effective for the warming of the mesosphere observed by Nordberg and Smith (Reference 6 ).

If the wind velocity of the jet stream exceeds $200 \mathrm{~m} / \mathrm{sec}$ for several days; the layer around the mesopause can be warmed significantly even by acoustic waves.

\section{REFERENCES}

1. Kellogg, W. W., "Chemical Heating above the Polar Mesopause in Winter," J. Meteorol. 18(3):373-381, June 1961.

2. Young, C., and Epstein, E. D., "Atomic Oxygen in the Polä Winter Mesosphere," J. Atmos. Sci. 19(6):435-443, November 1962 .

3. Maeda, K., "Auroral Dissociation of Molecular Oxygen in the Polar Mesosphere," J. Geophys. Res. 68(1):185-197, January 1, 1963.

4. Haurwitz, B., "Frictional Effects and the Meridional Circulation in the Mesosphere," J. Geophys. Res. 66(8):2381-2391, August 1961.

5. Kochanski, A., "Circulation and Temperatures at 70- to 100-Kilometer Height," J. Geophys. Res. 68(1):213-226, January 1, 1963.

6. Nordberg, W., and Smith, W., "Preliminary Measurements of Temperatures and Winds above $50 \mathrm{~km}$ over Wallops Island, Virginia," NASA Technical Note D-1694, March 1963.

7. Hines, C. O., "Comments" Annual AGU Meeting, April 1962.

8. Hines, C. O., "The Upper Atmosphere in Motion," Quart. J. Roy. Meteorol. Soc. 89:1-42, January, 1963.

9. Gossard, E. E., "Vertical Flux of Energy into the Lower Ionosphere from Internal Gravity Waves Generated in the Troposphere,"J. Geophys. Res. 67(2):745-757, February 1962. 
10. Blamont, J. E., and De Jage, C., "Upper Atmospheric Turbulence near the $100 \mathrm{~km}$ level," Annales de Geophys. 17(1):134-144, 1961.

11. Daniels, F. B., "Acoustical Energy Generated by the Ocean Waves," J. Acoust. Soc. Am. 24:38, 1952.

12. Eckart, C., "The Theory of Noise in Continuous Media," J. Acoust. Soc. Am. 25:195-199, March 1953.

13. Cook, R. K., and Young, J. M., "Microbaroms and Sound Radiated by Ocean Waves," Annual AGU Meeting, Washington D. C., April 19, 1963.

14. Golitsyn, G. S., 'Possibility of the Heating of the Upper Atmosphere by Long Wave Acoustic Radiation,"Akad. Nauk USSR, Izvest. Ser. Geofiz. 7:1092-1093, July 1961; Translated in Bull. Acad. Sci. USSR, Geophys. Ser. 7:720-721, 1961.

15. Charney, J. G., and Drazin, P. G., 'Propagation of Planetary-Scale Disturbances from the Lower into the Upper Atmosphere," J. Geophys. Res. 66(1):83-108, January 1961.

16. Boville, B. W., Wilson, C. V., and Hare, F. K., "Baroclinic Waves of the Polar Night Vortex," J. Meteorology 18(5):567-580, October 1961.

17. U. S. Weather Bureau, 'Daily 100-mb and 50-mb Three Times Monthly 30-mb Synoptic Weather Maps of the IGY period," Washington: U. S. Department of Commerce, 1961.

18. Krishnamurti, T. N., "A Vertical Cross Section Through the 'Polar-Night' Jet Stream," $J$. Geophys. Res. 64(11):1835-1844, November 1959.

19. Eckart, C., "Hydrodynamics of Oceans and Atmospheres," New York: Pergamon Press, 1960.

20. Hines, C. O., 'Internal Atmospheric Gravity Waves at Ionospheric Heights," Canad. J. Phys. 38(11):1441-1481, 1960.

21. Martyn, D. F., "Cellular Atmospheric Waves in the Ionosphere and Troposphere," Proc. Roy. Soc. A201:216-233, November 1960.

22. Stroud, W. G., Nordberg, W., and Bandeen, W. R., 'Rocket-Grenade Measurements of Temperatures and Winds in the Mesosphere over Churchill, Canada," J. Geophys. Res. 65(8):2307-2323, August 1960.

23. Maeda, K., "On the Heating of the Polar Upper Atmosphere," NASA Technical Report R-141, 1962.

24. Lighthill, M. J., "On Sound Generated Aerodynamically. I. General Theory," Proc. Roy. Soc. A211:565-587, March 20, 1952.

25. Lighthill, M. J., "On Sound Generated Aerodynamically. II. Turbulence as a Source of Sound," Proc. Roy. Soc. A222:1-32, February 23, 1954. 
26. Proudman, I., "The Generation of Noise by Isotropic Turbulence," Proc, Roy. Soc. A214:119-132, August 7, 1952.

27. Schatzman, E., "The Propagation of a Shock-Wave in an Atmosphere of Varying Density," Nuovo Cimento 22(Serielo):209-237, 1961.

28. Kulsrud, R. M., "Effect of Magnetic Fields on Generation of Noise by Isotropic Turbulence," Astrophys. J. 120(2):461-480, March 1955.

29. Batchelor, G. K., and Bondi, H., "The Theory of Homogeneous Turbulence," Harvard: Cambridge University Press, 1956.

30. Heisenberg, W., "On the Theory of Statistical and Isotropic Turbulence," Proc. Roy. Soc. A195(1042):402-406, December 22, 1948.

31. Rayleigh, J. W. S., "The Theory of Sound," 2nd ed., New York: Dover Publications, 1945.

32. Ishikawa, G., "Solar Corpuscular Radiation as a Heat Source of the Upper Atmosphere," Papers Meteorol. Geophys. 19(2):93-123, December 1959.

33. Golitsyn, G. S., "Sound Absorption in the Atmosphere and Ionosphere," Akad. Nauk USSR, Izvest. Ser. Geofiz. 6:942-946, June 1961; Translated in Bull. Acad. Sci. USSR, Geophys. Ser.6:618-621, 1961.

34. Riehl, H., "Jet Streams of the Atmosphere," Dept of Atmospheric Science, Colorado State University, Technical Rept. No. 32, May 1962. 

Appendix A

\section{Notation}

$\mathrm{g}\left(0_{1}-\mathrm{g}\right) \quad$ Acceleration of gravity, $\mathrm{g}=98 \mathrm{~cm} / \mathrm{sec}^{2}$.

y Ratio of specific heats of air, $C_{p} C_{v}=1.4$, where $C_{p}$ and $C_{v}$ are the specific heat of air at constant pressure and that at constant volume, respectively.

R Gas constant of air, $2.87 \times 10^{6} \mathrm{ergs} / \mathrm{mol}^{\circ} \mathrm{C}$.

$\mathrm{J}_{0} \quad$ Joule's mechanical equivalent of heat, $4.185 \times 10^{7} \mathrm{ergs} / \mathrm{cal}$.

$\vec{f} \quad$ Resultant of all external forces (dyne/gm).

$\vec{v}(u, w) \quad$ Velocity vector, where $u$ is horizontal (southward) and w is vertical (upward) component of air motion in $\mathrm{cm} / \mathrm{sec}$.

$x(x, z) \quad$ The divergence of velocity per sec, i.e.,

$$
\mathbf{x}=\frac{\gamma u}{\gamma \mathbf{x}}+\frac{\gamma \omega}{\gamma \mathbf{z}}
$$

where $\mathrm{x}$ and $\mathrm{z}$ are horizontal (southward) and vertical (upward) coordinate, respectively.

P, $\rho, T$ Small departure from static value of pressure, density and temperature, function of $\mathrm{x}$ and $z$.

$P_{0}, \rho_{0}, T_{0} \quad$ Static pressure, density and absolute temperature, which are the functions of $z$ only in dyne $/ \mathrm{cm}^{2}, \mathrm{gm} / \mathrm{cm}^{3}$, and ${ }^{\circ} \mathrm{K}$, respectively.

$\overline{\mathbf{P}}, \bar{\rho}, \overline{\mathbf{T}}$ Total pressure, density and absolute temperature, $\overline{\mathbf{P}}=\mathbf{P}_{0}+\mathbf{P}, \bar{\rho}=\rho_{0}+\rho$ and $\overline{\mathbf{T}}=\mathrm{T}_{0}+\mathrm{T}$.

$\kappa \quad$ Heat conductivity of air (cal/ $/ \mathrm{cm} \mathrm{sec}^{\circ} \mathrm{K}$ ).

$\lambda \quad$ Horizontal wave length of pressure wave $(\mathrm{km})$.

$\tau$ Period of pressure wave (sec).

k Horizontal wave number, corresponding to $\lambda, \mathrm{k}=2 \pi / 2$ per $\mathrm{km}$.

$\omega$ Angular frequency of pressure wave, corresponding to $\tau, 2 \pi / 2$ per sec.

c Velocity of sound wave in the atmosphere $(\mathrm{cm} / \mathrm{sec})$. 
$\mathrm{H}$ Scale height of isothermal atmosphere, $\mathrm{H}=\mathrm{RT}_{0} / \mathrm{g}$.

D, Dt The Eulerian derivative, $\gamma / \gamma t+\vec{v} \cdot \vec{\nabla}$.

$\mu$ Viscosity of air, in dyne-sec $/ \mathrm{cm}^{2}$ i.e. poise $(\mathrm{gm} / \mathrm{cm}-\mathrm{sec})$.

$\nu$ Kinematic viscosity of air, $\nu=\mu / \rho_{0}\left(\mathrm{~cm}^{2} / \mathrm{sec}\right)$.

$a^{2} \quad$ Thermal conductivity of air, $a^{2}=\kappa / C_{p} \rho\left(\mathrm{cm}^{2} / \mathrm{sec}\right)$. 